Robert Rhoades

\title{
Integrating Local Voices and Visions Into the Global Mountain Agenda
}

FIGURE 1 In one of the world's most challenging and fragile environments, indigenous communities in the Andes are continuing a long tradition of potato cultivation. Sharing indigenous knowledge of and experience with such forms of cultivation is an important component of mountain-to mountain initiatives. (Photo by AGRUCO, Bolivia)
As the 21st century begins, mountain scholars and development specialists can congratulate themselves for having finally brought mountain issues to a global level of awareness. Through the efforts of a small number of dedicated individuals and institutions, the neglected mountain ecosystems and native peoples of the world were finally given official recognition at the 1992 Rio Earth Summit through Chapter 13 of Agenda 21 and again in 1998 by the UN General Assembly, which declared 2002 as the
"International Year of Mountains." Today, the professional international mountain circuits, both the scholarly and development kinds, are buzzing with conferencing, e-conferencing, report writing and publishing, public awareness raising, and a host of other activities that could convince us that conditions have never been better for the mountain cause. While we should all applaud this much-needed progress at the political level, some very important unfinished business remains on the mountain agenda.

Sowin' on the mountain, reapin' in the valley You're gonna reap just what you sow

Look what their greed has done to our mountains You're gonna reap just what you sow

Stripping on the mountain, polluting of the valley You're gonna reap just what you sow

Help your friends, they're gonna need you And someday you'll need them too*
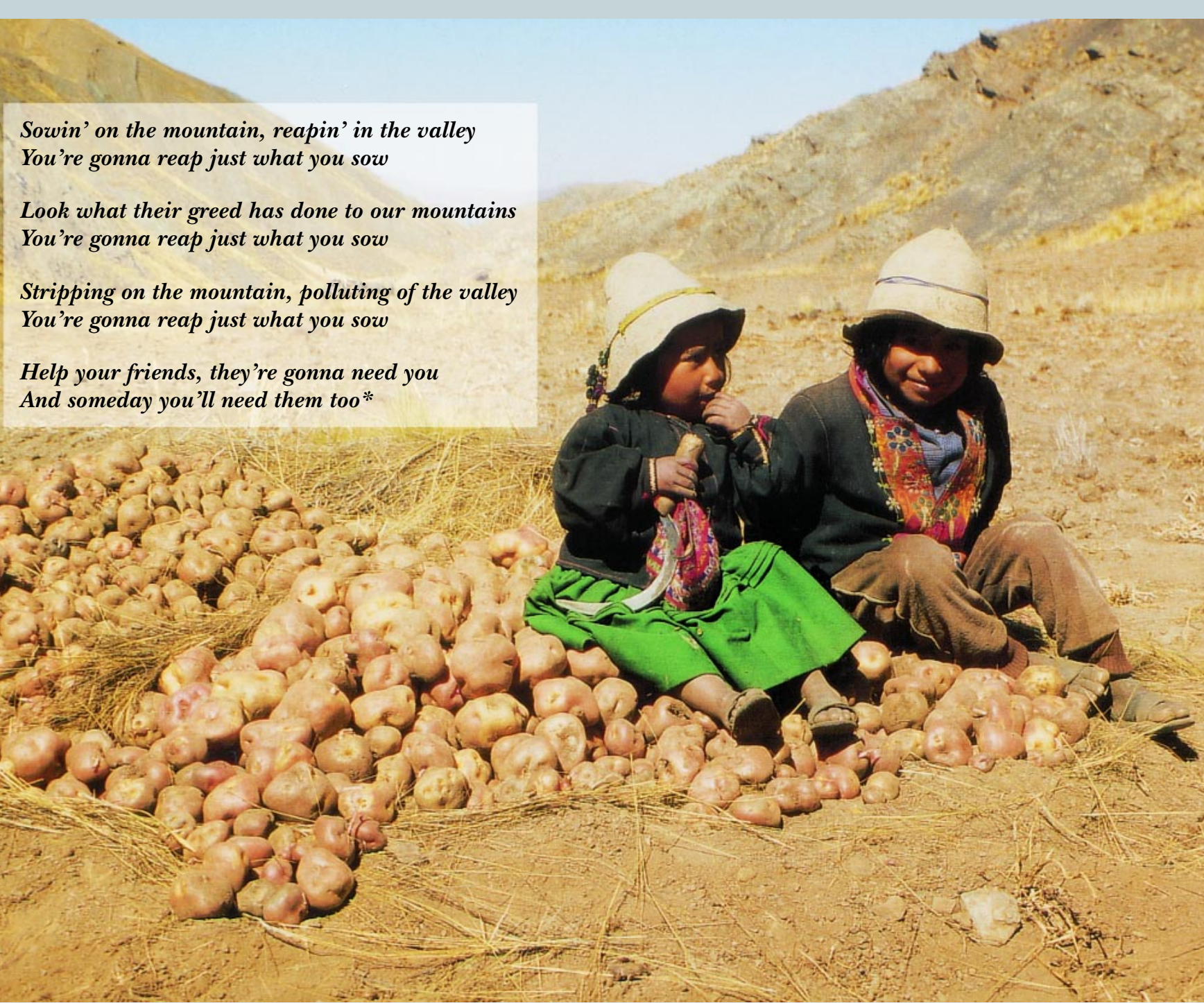


\section{Introduction}

Having won, at least partially, the political battle at the highest levels of government does not mean that mountains and their inhabitants will be any better off at the end of the next century. Our recent successes should not deter us from moving on to more demanding, innovative programs that will make a significant difference in mountain villages and landscapes. Political gains must be linked with effective practical action at the grassroots level. Otherwise, the self-congratulatory mood circulating among mountain specialists today could vanish quickly.

In this brief essay, I argue that, unless the mountain professional community devotes a good portion of its energy to creating new ways of thinking and acting for the direct benefit of mountain people, the international glitter of Chapter 13 and the UN Year of Mountains may be perceived as little more than disguised excuses to hold 5-star hotel meetings in attractive Alpine resort cities. The time is ripe to break new ground, move out of the well-trodden ruts of modern development paradigms, and create truly innovative approaches that directly engage mountain peoples themselves. No approach to mountains can be said to be integrated unless the voices of the mountain people themselves are present and heard.

\section{Sustainable mountain development: an unfinished job}

Mountain defenders, whether pure researchers or specialists in applied development, have long complained that the rest of the world does not understand the unique conditions of mountains and has therefore unsuccessfully tried to force "flatland" assumptions, programs, and thinking onto the vertical world of the highlands. As a rather caustic, critical voice speaking against the outside "lowland" mentality and its homogenizing, one-plan-fits-all vision, I have argued that we must understand mountain ecosystems and cultures in their own unique and complex contexts. But "echoes across the mountains," meaning those striking parallels in ecology, subsistence, ideology, social and cultural patterns, and marginality that reveal the common struggles and solutions of mountain people around the world, must also be perceived. One can only marvel at the great ingenuity of mountain peoples in carving out sustainable livelihoods in perhaps the most demanding environment in the inhabitable world. Their feats of engineering, intricate systems of food production, genius in architecture, and contributions to religion and the arts are at least the equivalent of many other wonders of the world. Time and time again, I have argued that a cross-mountain perspective can help avoid mistakes through better informed policy and more efficient development and transfer of technology.

One reason I feel so strongly about walking the tightrope between specificity and generality is my cross-mountain traveling, which, since the early 1960 s, has shown me both the uniqueness and universality of highland living. Today, ie, by the late 1990s, hundreds of people and scores of institutions work among the mountains of the world, making their living in activities linked to the inspiration of Chapter 13, Agenda 21. I worry, however, that more money and more people working for mountains do not necessarily mean more creative or effective approaches to addressing mountain issues.

Our awareness and our budgets have risen but not necessarily the effectiveness of our programs. Many international organizations that always had the opportunity to work in mountains did not wake up to mountain problems until the promise of increased funding from Chapter 13 lured them from their apathy. I recently argued that the post-Rio Chapter 13 generation might be advised to think about 5 prioritized challenges facing the mountain professional community: (1) revisiting the rich mountain literature of this century, (2) understanding mountains comparatively, (3) studying mountain global change, and (4) creating appropriate institutions for sustainable mountain futures. Finally, and perhaps most importantly to me personally, I recommended (5) that innovative venues be created to make mountain people central to the planning for the future of mountains. 
from Nepal to our site, plans are now being developed to arrange for an exchange of indigenous mountain peoples. We are further linked with a program called HimalAndes, an innovative program for South-South cooperation in mountains led by Alejandro Camino and Mario Tapia of Peru. Its purpose is to promote cooperation between Andean and Himalayan people and organizations. HimalAndes in turn is linked to the efforts of ICIMOD. I also believe that South-North cooperation in mountains will be fruitful. In this regard, we have an ongoing collaboration in the southern Appalachian area with Foxfire Fund of Rabun County, GA, USA. Actual implementation of a mountain-to-mountain exchange has thus begun.

\section{The mountain-to-mountain initiative: an example}

SANREM's mountain-to-mountain exchange program aims to create opportunities for cooperation and true active exchange between mountain peoples of the world. The purpose is for mountain people to learn directly from each other, to share experiences, and to debate approaches, methods, and institutions that have succeeded in one place that might be transferred to another.

Recently, Magdalena Fueres, an indigenous leader of Ecuador's Cotacachi Indian community, visited the southern Appalachian region of northern Georgia, USA. This was the first time I witnessed an encounter directly between truly local rural mountain peoples of geographically and culturally distinct regions. The purpose of the visit was to introduce Magdalena Fueres, who is Vice President of the Union of Campesino Organizations of Cotacachi (UNORCAC), to the Foxfire project. UNORCAC represents more than 20,000 highland Indians and mestizo campesinos who live in 43 villages on the eastern slope of the Cotacachi volcano. Magdalena's people have lived there for more than 5000 years. Foxfire is an organization that has worked in Appalachia since 1966, encouraging local young people to record for posterity the wisdom of the elders in the community. The elders also happen to be the parents, grandparents, relatives, and friends of the students. The original objective was to teach school children in the Rabun Gap High School how to write English while learning about their mountain heritage. The Foxfire effort has been tremendously successful in reaching out to the community, in developing a novel way for young people to establish links with the past, and in keeping indigenous knowledge-whether about agriculture, songs, play, or life ways-from slipping away. In the Foxfire English and journalism classes, the children first wrote up materials in a magazine (The Foxfire Magazine). Many of these materials were later published in a series of books. More than 8 million copies of the Foxfire books have been sold, and a new volume, Foxfire 11, appeared in 1999.

During Magdalena's visit with the Foxfire community on Black Bear Mountain just above Mountain City, GA, USA, an immediate feeling of kinship was established between our Andean collaborator and the local people. In explaining how Foxfire was launched, Robert Murray, the Foxfire Center Conservator who is of southern Appalachian heritage, wisely carried his conversation right to the mountain itself. This simple touch made the Andean visitor feel at home. In his wellknown folk tour of Black Bear Mountain, Robert fascinated her with a demonstration of children's handmade toys and rope making; he showed us many handhewn log cabins and demonstrated cures based on medicinal mountain plants. Magdalena immediately connected these Appalachian skills with her own people and culture back in the Andes. Comparison was natural and virtually effortless. Even the local legends of the mountains showed striking similarities.

As we walked along the winding mountain paths, Robert explained that, when Foxfire started in the mid-1960s, the Appalachian hill people were undergoing a "period of shame." They believed their hand-me-down knowledge, hard won through everyday experience, had little value compared to the higher status knowledge found in America's cities and flatlands. To be accepted, they thought they had to shed their "hillbilly" habits

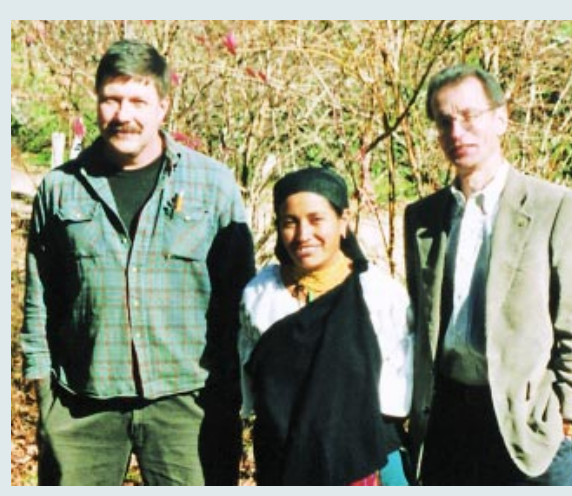

FIGURE 3 A South-North exchange in the Southern Appalachians: Magdalena Fueres, an indigenous leader of Ecuador's Cotacachi Indian community, with Robert Murray, Foxfire Center Conservator, and Mike Bucholz, Resource Director of Foxfire Fund. (Photo by Robert Rhoades)

"... when Foxfire started in the mid-rg6os, the Appalachian hill people were undergoing a 'period of shame.' They believed their hand-medown knowledge, hard won through everyday experience, had little value compared to the higher status knowledge found in America's cities and flatlands." 


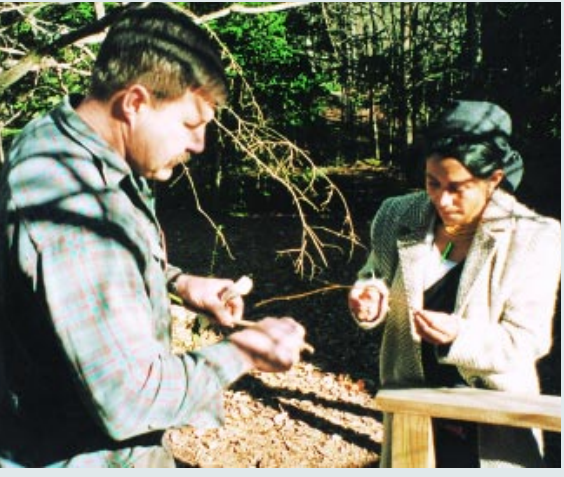

FIGURE 4 Robert Murray, of Southern Appalachian Heritage, discusses herbal medicine with Magdalena Fueres of Ecuador in Rabun County, GA, USA. (Photo by Robert Rhoades)

"The main point of local initiatives linking culture and education is that the students and the community feel true ownership." and adopt those of outsiders. Learning had to come from textbooks or other materials designed and produced by cityeducated teachers who knew little of or cared little for Rabun Gap. Highland cultures had to be replaced by a national culture promoted by the mass media. The Foxfire effort helped end the period of shame and restored pride to the mountain people.

Although Magdalena could speak no English, she recognized the shared mountain humanity. She told us poignantly that her own people today are in the period of shame. The conversation then turned to other commonalities between the two mountain areas. There are similarities in treatment by outsiders (indio and hillbilly are still widely used derogatory terms in both societies), parallels in types of socioeconomic change (loss of community and expropriation of local resources by distant companies), loss of culture (disappearance of mountain ways), and intervention from the outside (teaching methods and materials are dictated by the outside world). Listening to my mountain friends, I realized that the listing of parallels was not an academic exercise destined for a publication (such as I might write) but one of deep understanding and empathy on the part of both individuals.

The exchange, however, quickly moved beyond a mere verbal sharing of experiences to making concrete plans. Magdalena asked many questions that day for the simple reason that she too saw the value of having a project similar to Foxfire among her people in Cotacachi, Ecuador. She understood this was not some idea proposed by a foreign development worker but a living in situ model developed by mountain people for mountain people. In the Andes, as in Appalachia 30 years ago, a dramatic loss of culture, identity, and sense of place is occurring. And these developments are all social phenomena accompanied by environmental deterioration. Magdalena said later:

We have always had a similar desire to preserve our ancient knowledge, our myths and legends, our traditional crops and plants, and a sense of identity among our young people with
Cotacachi as an ancestral home, but we did not know how to do it. This visit to Foxfire has given us many practical ideas on exactly how to record, preserve, and make the community feel a part of the project. When I get back, we will begin our own Foxfire.

In further discussing how a program similar to Foxfire might be implemented in Cotacachi, Magdalena was concerned about one point:

We have no educated people; many are illiterate. If we needed someone to do more technical work, say with computers, then we would have to get a mestizo (mixed race) or blanco (white) from the town. We don't want to do that, but we have few choices.

Her point led to further discussion. The Foxfire people argued that any basic skills, such as writing, can be taught while instilling pride in mountain ways. Above all, they encouraged her to start small, which is what Foxfire did 30 years ago. The main point of local initiatives linking culture and education is that the students and the community feel true ownership. The process is not something conceived, controlled, and dictated from the outside and paid for by foreigners. It is truly indigenous.

However, everyone agreed that Magdalena had a point in stressing the very serious problems facing many mountain groups, such as illiteracy and few educated indigenous people to lead such projects. Even for mountain-to-mountain exchange to work, we will need more indigenous leaders who have a level of education that helps them to speak for mountain people on a broader basis. In this regard, our Filipino mountain colleagues in SANREM pointed to the fascinating program at Bukidnon State University, Philippines, in which tribal mountain youth are given scholarships and a curriculum based largely on their own cultural traditions but with new, outside skills as well (math, writing, engineering). Instead of learning American literature or lowland Philippine history, as in the past, they study their tribal legends and laws, along with the science 
and laws of the larger society. With some novel thinking, this model can be duplicated at little cost throughout the mountain regions of the world. At the end of their program, the students asked to return with their degree in hand to work with their home communities.

\section{Further steps for the future}

The mountain-to-mountain initiative is a small step forward. It may not change the course of history for mountain people. But if we are going to speak of integration, then we should listen to mountain people and follow their leads in determining development as they wish. We have tried just about every conventional approach there is. Why not this one?

Most international professional mountain scientists and planners have witnessed how valuable it is for them or their national counterparts to visit other mountain areas (eg, Himalayan scientists in the Alps). Why not extend this idea to the next logical step and make it possible for mountain people themselves to learn directly from each other? order:

Finally, a few recommendations are in

1. All integrated mountain projects funded by bilateral or international agencies should include a component of the mountain-to-mountain initiative;

\section{AUTHOR}

\section{Robert Rhoades}

Department of Anthropology, University of Georgia, Athens, GA, USA.rrhoades@uga.edu

Robert Rhoades is Professor of Anthropology and Program Director of SANREM-Andes at the University of Georgia, Athens, Georgia, USA. Since the early 1960s, he has visited geographically separate and remote mountain regions of South America, North America, Europe, Asia,
2. Initiatives already on the ground, such as the HimalAndes or SANREM programs, should be encouraged and used as models for other regions;

3. Special gatherings of indigenous people should be included as central elements of the Year of Mountains celebrations;

4. A global mountain-to-mountain network involving rural mountain communities should be created and be accorded the status of full and equal membership in the Mountain Agenda.
FIGURE 5 A South-South mountain-to-mountain exchange: indigenous leader Magdalena Fueres presents a traditional Andean cereal known as goosefoot, or quinoa, to Dr Virginia Nazarea, a Filipino researcher, in the village of La Calera, Canton Cotacachi, Imbabura Province, Ecuador. (Photo by Robert Rhoades)

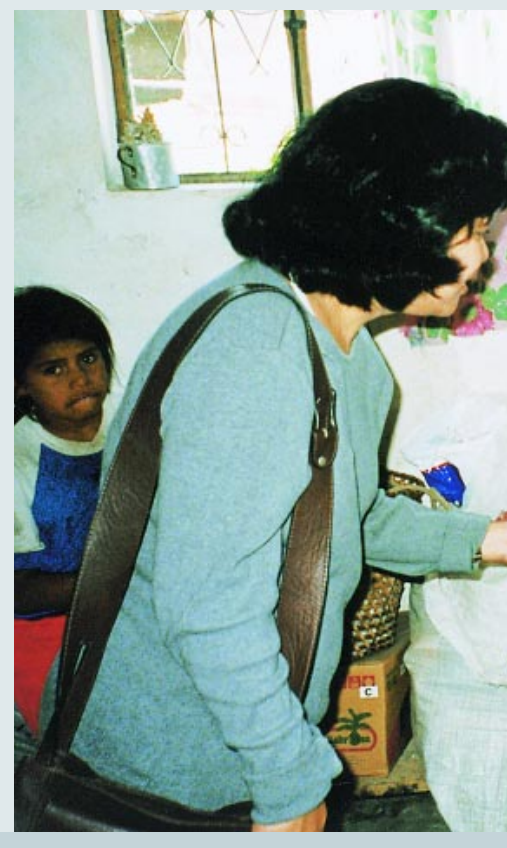

and Africa, spending days and nights with highland peoples, recording their views and the changes they are undergoing. He enthusiastically became an unofficial and self-appointed "broker" between widely scattered mountain peoples. In the 1970s, he was one of a handful of scholars dedicated to carrying on the comparative moun tain tradition of Alexander Humboldt or Karl Troll.

\section{FURTHER READING}

Collins KC, Hunter L, Foxfire Students, editors. 1999. Foxfire 11. New York: Anchor Books. With an introduction by R. Rhoades.

Denniston D. 1995. High Priorities: Conserving Mountain Ecosystems and Cultures. World Watch Paper 123. Washington, DC: World Watch Institute.

Hamilton LS. 1993. Overview of mountain protected areas and mountain initiatives leading to and furthering
Agenda 21. International Conference on Mountain National Parks and Biosphere Reserves: Monitoring and Management; 20-23 September 1993; Krkonse National Park, Czech Republic.

Rhoades R. 1997. Pathways Towards a Sustainable

Mountain Agriculture for the 21st Century: The Hindu Kush-Himalayan Experience. Kathmandu: International Center for Integrated Mountain Development. 